\title{
BMJ Open Feasibility of nephrinuria as a screening tool for the risk of pre-eclampsia: prospective observational study
}

Tianyue Zhai, Itsuko Furuta, Rina Akaishi, Kosuke Kawabata, Kentaro Chiba, Takeshi Umazume, Satoshi Ishikawa, Takahiro Yamada, Mamoru Morikawa, Hisanori Minakami

To cite: Zhai T, Furuta I, Akaishi R, et al. Feasibility of nephrinuria as a screening tool for the risk of preeclampsia: prospective observational study. BMJ Open 2016;6:e011229. doi:10.1136/bmjopen-2016011229

- Prepublication history for this paper is available online. To view these files please visit the journal online (http://dx.doi.org/10.1136/ bmjopen-2016-011229).

Received 21 January 2016 Revised 10 June 2016 Accepted 17 June 2016

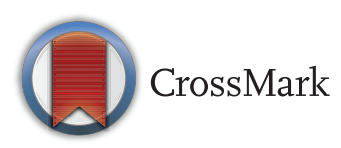

Department of Obstetrics, Hokkaido University Graduate School of Medicine, Sapporo, Hokkaido, Japan

Correspondence to Dr Itsuko Furuta; furuchan@med.hokudai.ac.jp

\section{ABSTRACT}

Objectives: To investigate the possibility of nephrinuria as a screening tool for the risk of pre-eclampsia $(\mathrm{PE})$.

Design: Prospective observational study.

Setting: A single university hospital. Changes in urinary nephrin:creatinine ratio (NCR, $\mathrm{ng} / \mathrm{mg}$ ) and protein:creatinine ratio $(P C R, \mathrm{mg} / \mathrm{mg})$ in pregnancy were determined. Significant proteinuria in pregnancy (SPIP) was defined as PCR $>0.27$. PE was diagnosed in women with both SPIP and hypertension.

Participants: 89 pregnant women in whom neither hypertension nor SPIP was present at enrolment, providing 31,125 and 93 random urine samples during first, second and third trimesters, respectively.

Results: PE developed in 14 of the 89 women. NCR increased with increasing PCR in 14 women with PE (correlation coefficient, 0.862; $p<0.0001$ ). In contrast, NCR did not change significantly despite significant increases in PCR in 75 women with normotensive pregnancies defined as neither SPIP nor hypertension, indicating that there was little increase in nephrinuria over the physiological range of proteinuria in pregnancy. Relative risk of later development of PE among asymptomatic second and third trimester women with NCR $(\mathrm{ng} / \mathrm{mg})>122$ (95th centile value for 75 women with normotensive pregnancies) was 5.93 $(95 \% \mathrm{Cl} 2.59$ to $13.6 ; 60 \%(6 / 10)$ vs $10 \%(8 / 79))$ and $13.5(95 \% \mathrm{Cl} 3.31$ to $55.0 ; 75 \%(6 / 8)$ vs $5.5 \%$ $(2 / 36))$, respectively, compared with women with $N C R \leq 122$ at that time.

Conclusions: Nephrinuria was unlikely to increase in normal pregnancy. A certain NCR cut-off may efficiently differentiate women at higher risk of PE.

\section{INTRODUCTION}

Nephrin is a podocyte-specific transmembrane protein that is predominantly localised at the glomerular slit diaphragm of podocytes. ${ }^{1}$ The podocytes, glomerular epithelial cells located at the outermost layer of the glomerular basement membrane (GBM) and their foot processes form tight interdigitating

\section{Strengths and limitations of this study}

- This study was performed using all longitudinal urine samples provided by pregnant women who had neither significant proteinuria nor hypertension at the time of registration. The first urine samples were obtained from all participants at the time of registration.

- Since our cohort included a large number of women at high risk of pre-eclampsia (PE), a large proportion of these women $(16 \%)$ later developed PE. This allowed better characterisation of differences in the changes in urine nephrin:creatinine ratio (NCR) and protein:creatinine ratio during pregnancy between women who eventually did develop PE and those who did not.

- Since the study population did not represent the general population, this study did not demonstrate accurate screening characteristics of urine NCR for prediction of PE onset. Among the 14 women who developed PE, $43 \%$ (6/14) were aged $\geq 40$ years, $29 \%(4 / 14)$ had twin pregnancies and all of the remaining 6 women with singleton pregnancies and aged $<40$ years had risk factors for $\mathrm{PE}$, ie, systemic lupus erythematosus in 2 women, advanced maternal age ( $\geq 35$ years old) in 2 women, Sjögren's syndrome in 1 woman and diabetes mellitus in 1 woman.

networks and regulate the filtration of circulating plasma proteins from the capillary lumen into Bowman's space. ${ }^{2} 3$ Thus, podocytes together with the GBM determine the permselectivity of plasma proteins, and podocytopathies result in proteinuria and increased numbers of podocytes in the urine (podocyturia). ${ }^{4-6}$ Increased podocyturia has been confirmed in pregnant women with pre-eclampsia (PE). ${ }^{5}$ p-9

Nephrin expression was shown to be reduced in kidney biopsy specimens from women with PE and in autopsy specimens from women who died from PE. ${ }^{10}{ }^{11}$ Soluble 
nephrin (nephrinuria) is detected in the urine of pregnant women, and an increase in nephrinuria is seen in women with $\mathrm{PE},{ }^{12-15}$ indicating that reduced nephrin expression is associated with increased nephrin shedding from podocytes.

To the best of our knowledge, there have been four studies regarding urinary nephrin concentration in pregnant women. ${ }^{12-15}$ All of these studies acknowledged the possibility of urinary nephrin as a biomarker predicting onset of PE. ${ }^{12-15}$ However, since longitudinal data on urinary nephrin in pregnancy have not been reported, the behaviour of urinary nephrin in pregnancy is not well understood. The present study was performed to determine changes in nephrinuria and the associations with proteinuria in women with normotensive and $\mathrm{PE}$ pregnancies.

\section{METHODS}

This study was conducted in accordance with the principles of the Declaration of Helsinki and with the approval of the Institutional Review Board of Hokkaido University Hospital (013-3999, 30 April 2014), a tertiary teaching hospital managing mainly high-risk pregnant women.

\section{Participants}

A total of 89 women participated in this study. All participants gave written informed consent prior to enrolment and fulfilled the following three conditions: (1) gestational week $(\mathrm{GW})<22$ at enrolment; (2) with neither significant proteinuria in pregnancy (SPIP) nor hypertension at enrolment and (3) gave birth at Hokkaido University Hospital during the study period from May 2014 to October 2015.

\section{Definitions of terms used in this study}

SPIP was defined as a protein:creatinine ratio (PCR, $\mathrm{mg} / \mathrm{mg}$ ) $>0.27$ (corresponding to $30 \mathrm{mg} / \mathrm{mmol}$ ) in spot urine specimens. Hypertension was diagnosed in women with systolic blood pressure $\geq 140 \mathrm{~mm} \mathrm{Hg}$ and/or diastolic blood pressure $\geq 90 \mathrm{~mm} \mathrm{Hg}$ on at least two occasions recorded more than 12 hours apart. The GW at new onset of hypertension and SPIP were specified in each participant. PE was diagnosed in women who showed hypertension and SPIP on and after GW 20. Normotensive pregnancy was defined as neither hypertension nor SPIP throughout pregnancy.

\section{Urine collection and assay methods for nephrin, protein and creatinine}

All spot urine samples were coded and processed within 2 hours of collection. Urine samples were transferred to tubes and centrifuged at $700 \times \mathrm{g}$ for $5 \mathrm{~min}$. Urinary supernatant was stored at $-20^{\circ} \mathrm{C}$ until measurement of protein, creatinine and nephrin levels. Protein and creatinine concentrations were measured using a Protein Assay Rapid Kit Wako and Laboassay Creatinine (Wako Pure Chemical Industries, Osaka, Japan), respectively.
Nephrin concentration was measured using an ELISA kit (Exocell, Philadelphia, Pennsylvania, USA). Urine samples were diluted in the range of 1:10-1:50 depending on proteinuria in the sample. The intra-array and interassay coefficients of variation for nephrin were $<10 \%$. Since the detection limits were $0.26 \mathrm{ng} / \mathrm{mL}$ for nephrin and $5 \mu \mathrm{g} / \mathrm{mL}$ for protein, we assumed that samples with undetectable levels contained $0.13 \mathrm{ng} / \mathrm{mL}$ nephrin and $2.5 \mu \mathrm{g} / \mathrm{mL}$ protein. Protein and nephrin concentrations in the urine were corrected by urine creatinine concentration and expressed as PCR $(\mathrm{mg} / \mathrm{mg})$ and nephrin:creatinine ratio (NCR, $\mathrm{ng} / \mathrm{mg}$ ).

\section{Statistical analyses}

Data are presented as the median (range). Statistical analyses were performed using the JMP10 statistical software package (SAS, Cary, North Carolina, USA). The Wilcoxon/Kruskal-Wallis method was used for comparison of medians. The Mann-Whitney U test with Bonferroni's correction was used to compare median values between groups. Spearman's rank-order correlation was used to test associations between two variables. In all analyses, $p<0.05$ was taken to indicate statistical significance.

\section{RESULTS}

Of the 89 women included in the study, 14 later developed both SPIP and hypertension during pregnancy and were diagnosed as having $\mathrm{PE}$, while the remaining 75 developed neither SPIP nor hypertension and were judged as having normal pregnancies (table 1). The 14 and 75 women with PE and normotensive pregnancies provided 134 and 115 urine samples, respectively (table 1). Of the 75 normotensive control women, 18 provided three urine samples including one each collected during the first, second and third trimesters, five provided two urine samples including one each during the first and second trimesters, 18 provided two urine samples including one each during the second and third trimesters and the remaining 34 women provided only one urine sample collected during the second trimester. Thus, 134 urine samples from control women consisted of 23, 75 and 36 urine specimens collected during the first, second and third trimesters, respectively (table 1). Fourteen women who later developed PE provided a total of 115 urine samples (4-13 samples/woman; median, 7 samples) (table 1). Of the 115 urine samples, 73 were collected at a latent phase with neither SPIP nor hypertension. Six of the 14 women with PE developed SPIP first at GW 33.5 (26.0-29.1) and hypertension later at GW 37.1 (35.4-40.4). Six women developed SPIP and hypertension simultaneously at GW 30.8 (27.0-36.0). The remaining two women developed hypertension first at GW 32.9 and 34.2 and SPIP later at GW 35.3 and 36.1, respectively.

\section{Changes in NCR and PCR in normotensive pregnancies}

The urinary nephrin concentration ranged from 0.13 to $389.9 \mathrm{ng} / \mathrm{mL}$, protein concentration ranged from 2.5 to 
Table 1 Demographic characteristics of 89 women

\begin{tabular}{|c|c|c|c|}
\hline & Control & Pre-eclampsia & p Value \\
\hline Number of women & 75 & 14 & \\
\hline Maternal age (years) & $34(20-43)$ & 38 (19-43) & 0.6216 \\
\hline$\geq 35$ & $36(48 \%)$ & $8(57 \%)$ & 0.5299 \\
\hline$\geq 40$ & $8(11 \%)$ & $6(43 \%)$ & 0.0024 \\
\hline Nulliparous & $39(52 \%)$ & $13(93 \%)$ & 0.0018 \\
\hline Twin pregnancy & $0(0.0 \%)$ & $4(29 \%)$ & $<0.0001$ \\
\hline Body height $(\mathrm{m})$ & $1.58(1.45-1.68)$ & $1.58(1.48-1.66)$ & 0.7290 \\
\hline Prepregnancy weight (kg) & $51(40-100)$ & $54(34-67)$ & 0.7670 \\
\hline Body mass index $\left(\mathrm{kg} / \mathrm{m}^{2}\right)$ & $20.2(16.8-38.1)$ & $21.8(14.9-27.9)$ & 0.6332 \\
\hline$\geq 25$ & $9(12 \%)$ & $2(14 \%)$ & 0.8115 \\
\hline Complications & $56(75 \%)^{*}$ & $8(57 \%) \dagger$ & 0.1805 \\
\hline \multicolumn{4}{|l|}{ GW at onset } \\
\hline Hypertension & NA & $34(27-40)$ & \\
\hline SPIP & NA & $32.5(26-39)$ & \\
\hline GW at delivery & $38(36-41)$ & $36(30-40)$ & $<0.0001$ \\
\hline$<37$ & $3(4.0 \%)$ & $9(64 \%)$ & $<0.0001$ \\
\hline Infant birth weight $(\mathrm{kg})$ & $2.91(2.22-3.86)$ & $2.29(1.08-2.86)$ & $<0.0001$ \\
\hline Total number of urine samples & 134 & 115 & \\
\hline Number of samples/person & $2(1-3)$ & $7(4-13)$ & \\
\hline \multicolumn{4}{|l|}{ Timing of urine sampling } \\
\hline First trimester $(5-13)$ & 23/[23]‡ & 8/[7]‡ & \\
\hline Second trimester (14-27) & $75 /[75] \ddagger$ & $50 /[14] \ddagger$ & \\
\hline Third trimester (28-38) & $36 /[36] \ddagger$ & $57 /[14] \ddagger$ & \\
\hline Latent phase & $\mathrm{NA}$ & $73 /[14] \ddagger$ & \\
\hline SPIP alone phase & NA & $16 /[6] \ddagger$ & \\
\hline Hypertension alone phase & NA & $4 /[2] \ddagger$ & \\
\hline Pre-eclampsia phase & NA & $22 /[14] \ddagger$ & \\
\hline
\end{tabular}

Data are presented as the median (range).

${ }^{*}$ Complications included nine thyroid diseases, seven uterine fibromas, six congenital cardiac malformation, four diabetes mellitus/gestational diabetes mellitus, four autoimmune diseases (Sjogren's syndrome, immune thrombocytopenic purpura, antiphospholipid syndrome and rheumatoid arthritis), four depressions, four malignant neoplasms (after treatment), three familial protein S deficiency, three poor obstetrical history (fetal death in utero), 1 each with Wilson's disease, brain aneurysm, Moyamoya disease, Cushing's disease, lymphangitis, gene carrier of congenital immunodeficiency, recurrent pyelonephritis, epilepsy, pulmonary sarcoidosis, scoliosis, arrhythmia and asthma. These 56 women with complications showed a PCR level ( $\mathrm{mg} / \mathrm{mg}$, median (range)) of $0.026(0.001-0.111)$ at enrolment.

†Complications included three autoimmune diseases ( 2 systemic lupus erythematosus and 1 Sjogren's syndrome), three urogenital malformations (unilateral renal aplasia, duplicate uterus, and bicornuate uterus), 1 diabetes mellitus and 1 chronic thyroiditis. These eight women with complications showed a PCR level of $0.047(0.002-0.065)$ at enrolment.

$\ddagger$ In square brackets, the number of women who provided urine samples is indicated.

GW, gestational week; NA, not applicable; PCR, protein:creatinine ratio; SPIP, significant proteinuria in pregnancy defined as a protein-to-creatinine ratio $(\mathrm{mg} / \mathrm{mg})>0.27$.

$165.0 \mu \mathrm{g} / \mathrm{mL}$ and the creatinine concentration ranged from 0.138 to $3.26 \mathrm{mg} / \mathrm{mL}$ in urine samples from 75 normotensive control women. NCR did not change significantly during pregnancy in normotensive control women (figure 1A,B, upper panels). However, PCR increased with advancing GW (figure 1A,B, lower panels), and PCR in the third trimester was significantly higher than those in the first and second trimesters.

\section{Changes in NCR and PCR in PE pregnancies}

The urinary nephrin concentration ranged from 0.13 to $26691 \mathrm{ng} / \mathrm{mL}$, protein concentration ranged from 2.5 to $19903 \mu \mathrm{g} / \mathrm{mL}$ and creatinine concentration ranged from 0.079 to $3.58 \mathrm{mg} / \mathrm{mL}$ in urine samples from 14 women with PE. Both NCR and PCR increased gradually with advancing GW (figure 2). It was interesting to note that the NCR level was already significantly higher before onset of SPIP (at phase 2 in figure 2) than in control women (see legend for figure 2) as well as baseline NCR level in women with PE (at phase 1 in figure 2).

\section{Correlation of PCR with NCR and nephrin:protein ratio} (NPR) in control women and women with PE

NCR was positively correlated with PCR in women with $\mathrm{PE}$ with a correlation coefficient of 0.862 (figure 3, upper right). Since the correlation between PCR and NCR was strong in women with PE, the NPR (ng/ng) did not change significantly according to PCR in women with PE (figure 3, lower right). However, NPR decreased significantly with increasing PCR (figure 3, lower left), confirming that nephrinuria hardly increased even in the presence of a significant increase in PCR in normotensive control women. In the PCR range $>0.27$ in women with $\mathrm{PE}$, the correlation coefficient between PCR and NCR became stronger, reaching a value of 
A

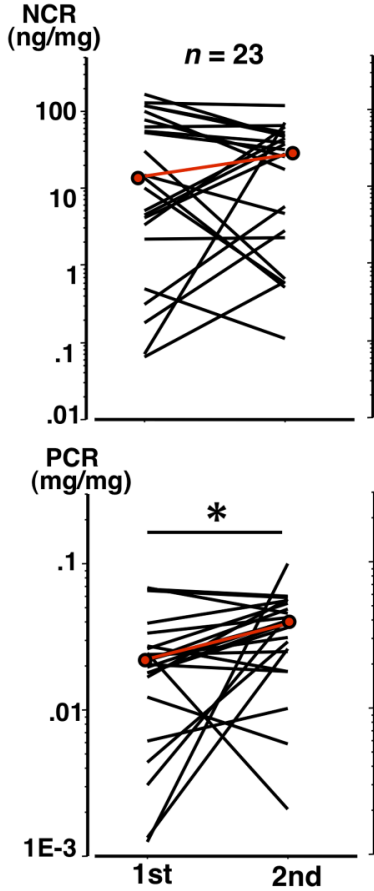

B

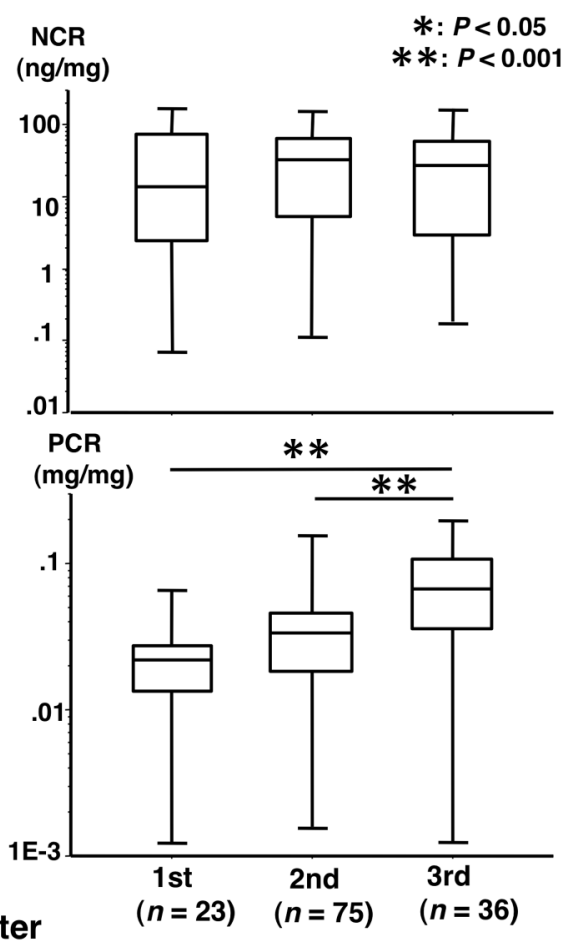

Figure 1 Changes in nephrin:creatinine ratio (NCR) and protein:creatinine ratio (PCR) in normotensive control women. $(A)$ The red line indicates changes in median values. Longitudinal paired urine samples for the first and second trimesters and for the second and third trimesters were available in 23 and 36 normotensive control women, respectively. The median NCR (ng/mg) was 13.8 vs 28.3 ( $p=0.2735$ ) for the first versus second trimester in the 23 women, respectively, and was 22.1 vs 26.6 $(p=0.2264)$ for the second versus third trimester in the 36 women, respectively. The median PCR $(\mathrm{mg} / \mathrm{mg}) \mathrm{was} 0.022 \mathrm{vs} 0.040$ $(p=0.0126)$ for the first versus second trimester in the 23 women, respectively, and was 0.040 vs $0.068(p<0.0001)$ for the second versus third trimester in the 36 women, respectively. In 18 women with three urine samples including one each collected during the first, second and third trimesters, NCR $(\mathrm{ng} / \mathrm{mg})$ did not change significantly $(14.3,30.0$ and 34.7 for the first, second and third trimesters, respectively), while PCR $(\mathrm{mg} / \mathrm{mg})$ increased significantly with advancing gestational week $(0.020,0.039$ and 0.065 for the first, second and third trimesters, respectively; $p=0.0096$ for the first versus second trimester level and $p=0.0065$ for the second versus third trimester level). (B) There were 34 other women in whom only second trimester urine samples were available. Data for these 34 women were combined with the data shown in (A). The median NCR (ng/mg) were 13.8, 32.3 and 26.6 for the first, second and third trimesters, respectively. The median PCR $(\mathrm{mg} / \mathrm{mg})$ was $0.022,0.033$ and 0.068 for the first, second and third trimesters, respectively. The median nephrin concentrations $(\mathrm{ng} / \mathrm{mL})$ were $10.4,25.1$ and 21.1 for the first, second and third trimesters, respectively. The median protein concentrations $(\mu \mathrm{g} / \mathrm{mL})$ were $20.6,21.9$ and 32.4 for the first, second and third trimesters, respectively.

0.904. In this range of proteinuria, nephrin accounted for $\sim 0.1-1.0 \%$ of protein weight (figure 3, lower right).

\section{Correlation of NCR and PCR with GW in control women} and possibility of NCR as a screening tool for prediction of PE onset

As expected, the NCR level was not correlated significantly with GW (figure 4, upper left), while the PCR level was significantly positively correlated with GW in normotensive control women $(\mathrm{R}=0.434, \mathrm{p}<0.0001)$ (figure 4, upper right). This implied that the 95th centile NCR level was constant, but the 95th centile PCR level changed with advancing GW during normotensive pregnancy.

To investigate the possibility that NCR was more efficient for differentiation of women at higher risk of PE than PCR, data on NCR and PCR of 14 women with PE at the latent phase were superimposed onto the upper panels of figure 4 (figure 4 , lower panels). This expectation was confirmed. Women with NCR $>95$ th centile value $(122 \mathrm{ng} / \mathrm{mg})$ compared with those with $\mathrm{NCR}<95$ th centile value showed relative risks (RR) of later developing PE of $5.93(\mathrm{p}<0.0001 ; 95 \%$ CI 2.59 to 13.6$)$ and 13.5 $(\mathrm{p}=0.0003 ; 95 \%$ CI 3.31 to 55.0$)$ for the second and third trimesters, respectively (see legend for figure 4). Women with $\mathrm{PCR}>95$ th centile value compared with women with $\mathrm{PCR}<95$ th centile value had $\mathrm{RR}$ of later developing PE of 4.06 ( $p=0.0024 ; 95 \%$ CI 1.64 to 10.0 ) for the second trimester. For the third trimester, however, PCR no longer significantly differentiated women with a higher and lower risk of PE (see legend for figure 4). 

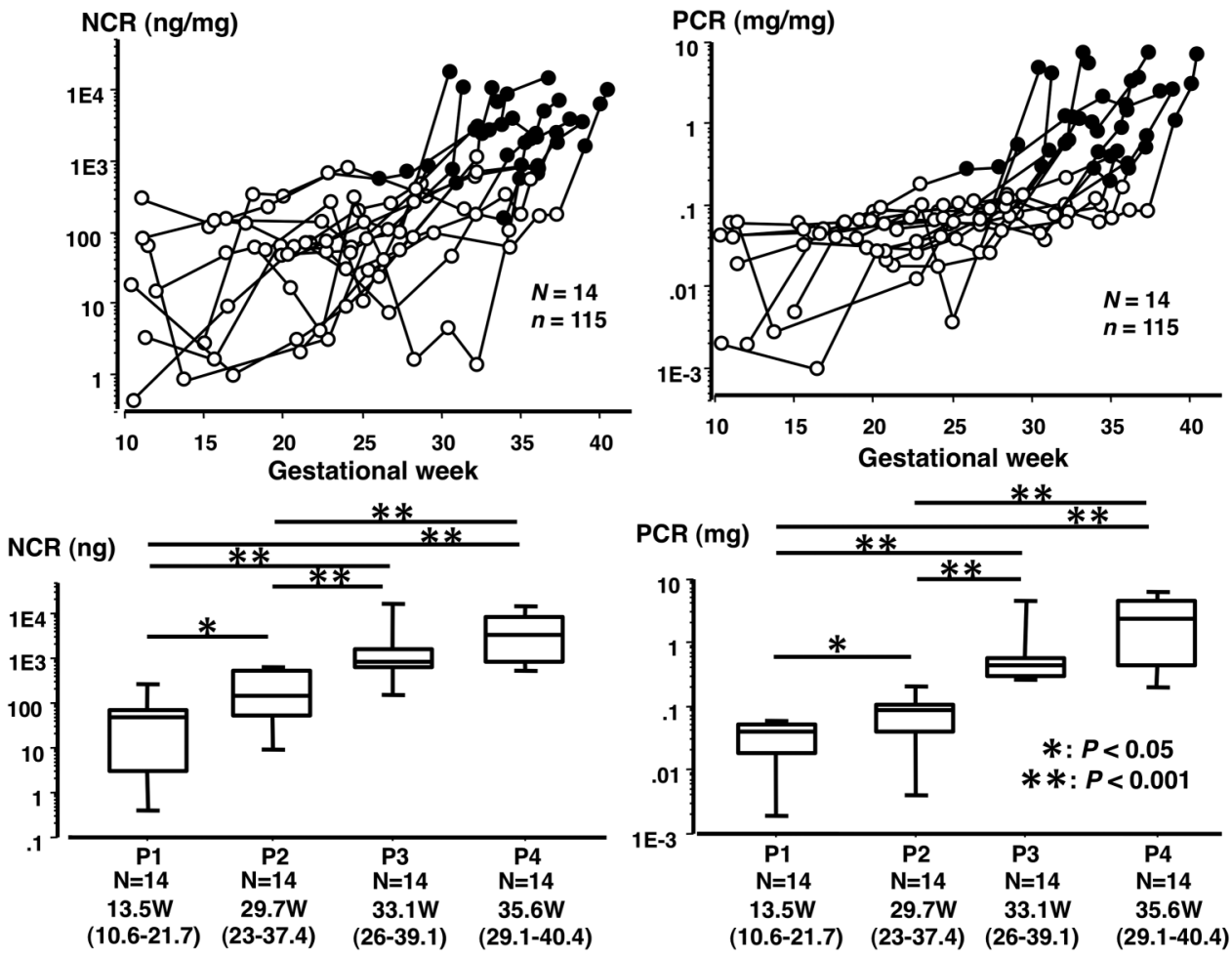

Figure 2 Changes in nephrin:creatinine ratio (NCR) and protein:creatinine ratio (PCR) in 14 women with pre-eclampsia (PE). Fourteen women with PE provided a total of 115 urine samples. Open and closed circles indicate urine samples before and after onset of significant proteinuria in pregnancy (SPIP), respectively (upper panels). Urine samples from individuals were classified into the following four clinical phases: phase 1 (P1), urine collected at the earliest gestational week (GW) of 13.5 (10.6-21.7); phase 2 (P2), urine collected at the latest GW of 29.7 (23.0-37.4), but before onset of SPIP; phase 3 (P3), urine exhibiting SPIP for the first time at GW of 34.0 (26.0-39.1); and phase 4 (P4), urine collected on the day closest to delivery at GW 35.6 (29.140.4). The median NCR (ng/mg) was 49.2, 142.1, 851.4 and 3368.7 for P1, P2, P3 and P4, respectively. The median PCR (mg/ $\mathrm{mg}$ ) was $0.041,0.087,0.436$ and 2.360 for P1, P2, P3 and P4, respectively. The median NCR of 142.1 for P2 was significantly higher than those in normotensive pregnancy $(14.3,32.3$ and 26.6 for the first, second and third trimesters, respectively). The median protein concentrations $(\mu \mathrm{g} / \mathrm{mL})$ were $26.3,56.4,301.4$ and 1237.8 for P1, P2, P3 and P4, respectively.

\section{DISCUSSION}

Since this study included a considerable number of women who were examined longitudinally, differences in changes in urinary NCR and PCR during normal pregnancies could be clearly observed; nephrinuria did not change significantly, while proteinuria increased with increasing GW in normotensive pregnancies. This dissociation between nephrinuria and proteinuria in normal pregnancy was noted for the first time in this study, and suggested that urinary NCR may be a more efficient means of detecting women at higher risk of developing PE compared with urinary PCR. In PE pregnancies, the degree of nephrinuria was closely correlated to that of proteinuria, especially at higher degrees of proteinuria with $\mathrm{PCR}>0.27$. The nephrinuria in the preclinical stage of PE pregnancies (before onset of SPIP) was already greater than that in normal pregnancy.

Proteinuria increases physiologically with advancing gestation $^{16}$ as confirmed in this study. In a study by Smith et $a l^{16}$ the mean PCR increased with advancing gestation in otherwise healthy women with singleton pregnancies; 0.065 in GW 16-20, 0.093 in GW 24-28 and 0.154 in GW 34-38. Spot urine PCR $(\mathrm{mg} / \mathrm{mg})>0.27$ has been proposed as an alternative for confirmation of protein loss $>300 \mathrm{mg} /$ day in 24-hour urine collection. ${ }^{17}$ International guidelines support the upper limit of normal proteinuria during pregnancy of $300 \mathrm{mg} / 24$ hours. $^{18-21}$ Some patients with PE exhibit SPIP first and hypertension later. ${ }^{22} 23$ This suggested that PCR can be used as a biomarker for prediction of PE. Indeed, 6 of the 14 women with PE developed SPIP first before development of hypertension in this study, and some benefits of the use of PCR for the prediction of PE were demonstrated in this study; a PCR cut-off specific for the second trimester differentiated women with higher from lower risk of PE. However, the observation that PCR increased with advancing gestation even in normal pregnancy decreased the usefulness of PCR in advanced GW; a PCR cut-off specific for the third trimester no longer differentiated women with higher from lower risk of PE among asymptomatic women in the third trimester in this study. This drawback, inherent to PCR, was suggested to be negligible in NCR for prediction of PE in this study.

The results of this study suggested that nephrinuria did not increase in normal pregnancy, but increased in 
Normotensive
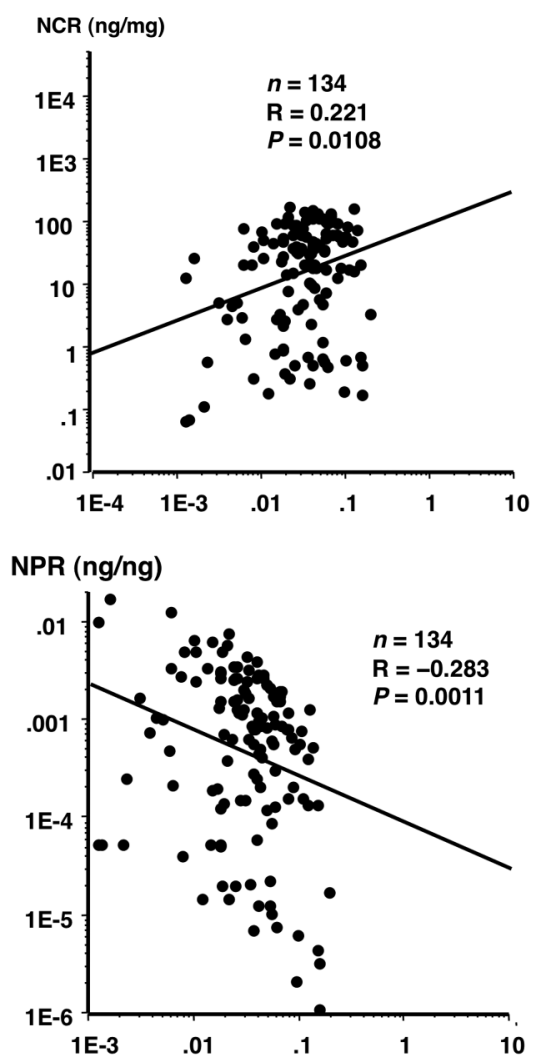

Pre-eclampsia

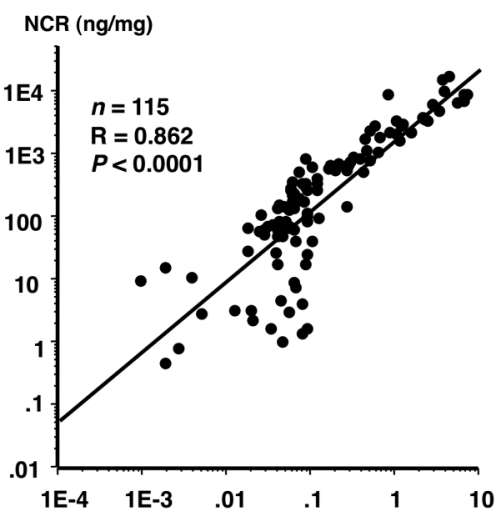

NPR (ng/ng)

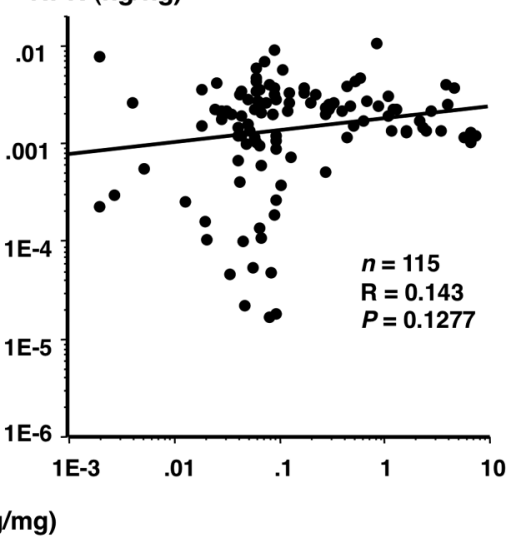

Figure 3 Correlations of nephrin:creatinine ratio (NCR) and nephrin:protein ratio (NPR) with protein:creatinine ratio (PCR) in normotensive and pre-eclampsia (PE) pregnancies. Oblique lines, linear regression lines between two variables. Upper panels: the correlation between PCR and NCR was much weaker in normotensive control women than in women with $P E$ (R=0.221 vs 0.862, respectively). In women who eventually developed PE, the correlation between PCR and NCR became stronger after onset of significant proteinuria in pregnancy (SPIP) compared with the clinical phase before SPIP onset; the R=0.577 for 77 urine samples before SPIP onset, which increased to 0.904 for 38 urine samples after SPIP onset. Lower panels: the NPR (ng/ng) did not change significantly according to PCR (right panel) in women with PE, while in normotensive control women, NPR decreased significantly with increasing PCR (left panel), suggesting that nephrinuria did not increase according to the amount of proteinuria over the physiological range, ie, $\mathrm{PCR}<0.27$.

PE pregnancy. Even before the onset of SPIP, NCR levels in women who subsequently developed PE were already higher than those in normal pregnancy (see legend for figure 2). This enabled efficient differentiation of women with higher from lower risk of PE in our small population; in women in the second and third trimesters asymptomatic with respect to PE (with neither SPIP nor hypertension), but with $\mathrm{NCR}>122 \mathrm{ng} / \mathrm{mg}$ (95th centile value for normal pregnancy), the risks of $\mathrm{PE}$ were 5.9-fold and 13.5-fold higher, respectively, than in women with $\mathrm{NCR}<122 \mathrm{ng} / \mathrm{mg}$.

In four previous studies regarding nephrinuria in pregnancy, the degree of nephrinuria was consistently greater in women with established PE. ${ }^{12-15}$ For example, in a study by Wang et $a l^{12}$ reporting nephrinuria in pregnancy for the first time in 2012, the mean NCR (ng/ mg) was 107 vs 1894 and mean nephrin concentration (ng/mL) was 86 vs 1226 for women with normotensive pregnancy vs women with PE pregnancy having a mean proteinuria of $2579 \mathrm{mg} /$ day, respectively. Screening characteristics of urinary nephrin were examined in two previous studies with promising results; ${ }^{13}{ }^{15}$ sensitivity and specificity were $73 \%$ and $79 \%$, respectively, in one study, ${ }^{13}$ and $57 \%$ and $58 \%$, respectively, in the other study for prediction of PE. ${ }^{15}$ In this study, the NCR cut-off of $122 \mathrm{ng} / \mathrm{mg}$ gave a sensitivity of $43 \%(6 / 14)$ and specificity of $95 \%(71 / 75)$ for the second trimester and $75 \%(6 / 8)$ and $94 \%(34 / 36)$ for the third trimester, respectively. Non-invasive urine tests, such as determination of NCR, may be useful for detecting women at higher risk of $\mathrm{PE}$.

\section{STUDY LIMITATIONS}

Since our institution is a tertiary centre managing mainly women at higher risk, the PE prevalence rate in our cohort was higher than that in the general population. Indeed, $72 \%(64 / 89)$ of women had at least one 

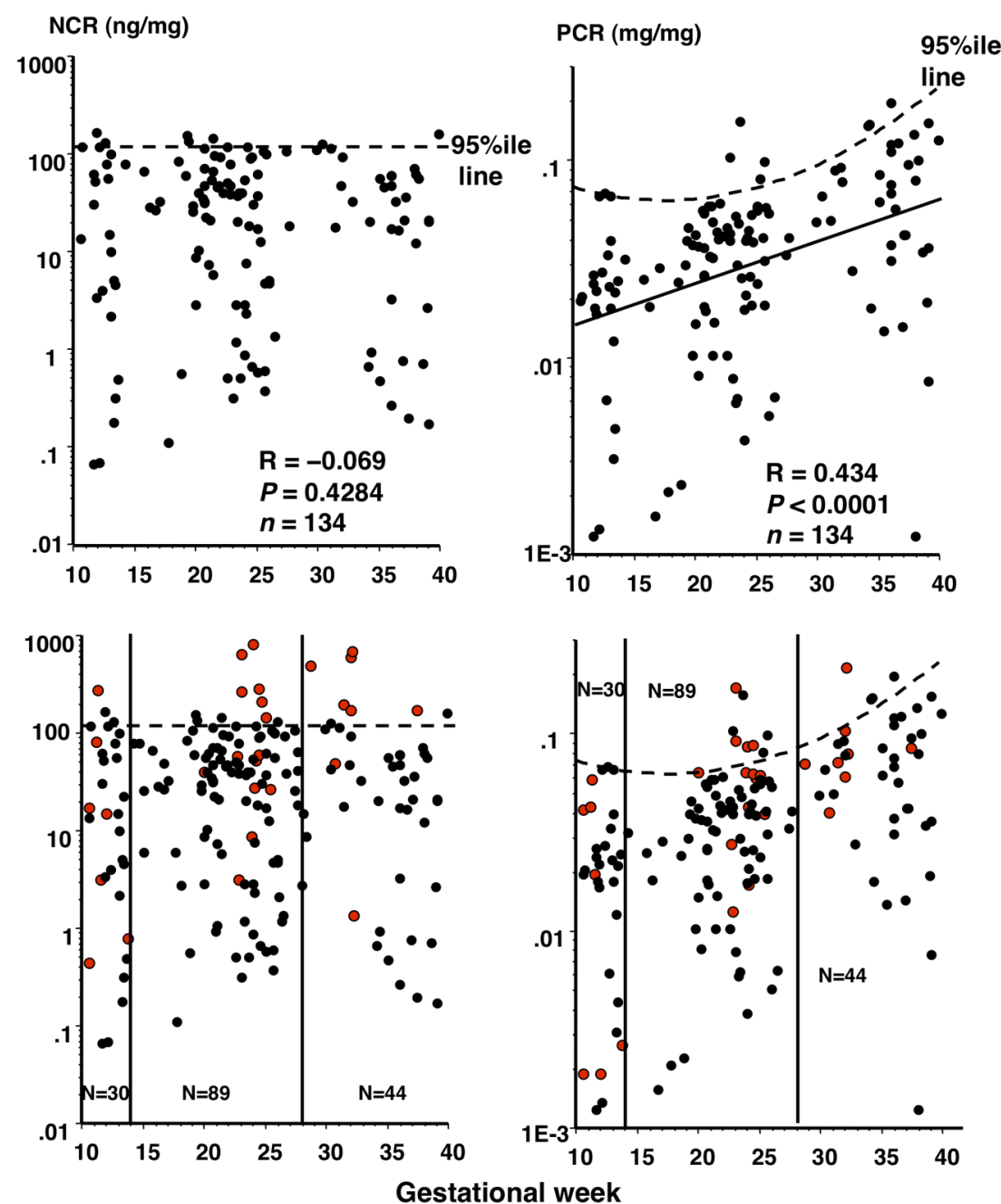

Figure 4 Correlation of nephrin:creatinine ratio (NCR) and protein:creatinine ratio (PCR) with gestational week in normotensive control women and possibility of NCR as a screening tool for prediction of pre-eclampsia (PE) onset. Upper panels: all 134 data on NCR and PCR of control women were plotted against gestational week. Dotted straight and curved lines indicate the 95th centile NCR and PCR levels, respectively, according to gestational week in normotensive control women. Since the NCR level did not change in pregnancy (no significant correlation between the NCR level and gestational week, $R=-0.069, p=0.4284$ ), the 95th centile NCR value was determined in 134 samples. Since PCR exhibited a significant correlation with gestational week, showing an oblique linear regression (solid line on the right, $R=0.434, p<0.0001$ ), the curved line was obtained showing the variable 95th centile PCR values according to gestational week. Lower panels: 28 data on NCR and PCR (red dots) of 14 women with PE were superimposed onto the upper panels. All 28 urine samples $(7,14$ and 8 samples from 7,14 and 8 women with PE during the first, second and third trimesters, respectively) were collected before onset of significant proteinuria in pregnancy (SPIP) and hypertension. Vertical lines separate pregnancy trimesters. When multiple urine samples were available within the same pregnancy trimester in a woman with PE, urine samples at the latest gestational week and at the day closest to gestational week 24 were chosen as first and third, and second trimester samples, respectively. Thus, totals of 30 (23 and 7 from control women and women with PE, respectively), 89 ( 75 and 14 from control women and women with PE, respectively) and 44 (36 and 8 from control women and women with PE, respectively) data are depicted for the first, second and third trimesters, respectively. The 95th NCR value $(122 \mathrm{ng} / \mathrm{mg})$ appeared to more efficiently differentiate between women with and without later development of PE than the 95th PCR value: for women with NCR above and below the 95th value, the risks of later development of PE were $33 \%$ (1/3) vs $22 \%$ (6/27) with $p=0.6496$ for the first trimester, $60 \%(6 / 10)$ vs $10 \%(8 / 79)$ with $p<0.0001$ (relative risk (RR), 5.93; $95 \% \mathrm{Cl} 2.59$ to 13.6 ) for the second trimester, and $75 \%(6 / 8)$ vs $5.5 \%(2 / 36)$ with $\mathrm{p}=0.0003$ (RR, 13.5 ; $95 \% \mathrm{Cl} 3.31$ to 55.0 ) for the third trimester, respectively, and for women with PCR above and below the 95th value, the values were $0.0 \%(0 / 2)$ vs $25 \%$ (7/28) with $\mathrm{p}=0.7409$ for the first trimester, $50 \%$ (4/8) vs $12 \%$ (10/81) with $\mathrm{p}=0.0024$ (RR, $4.06 ; 95 \% \mathrm{Cl}$ 1.64 to 10.0$)$ for the second trimester, and $33 \%(1 / 3)$ vs $17 \%(7 / 41)$ with $p=0.755$ for the third trimester, respectively.

complication listed in the footnote for table 1. Although not all of these complications were necessarily risk factors for PE, advanced maternal age, body mass index $\geq 25 \mathrm{~kg} / \mathrm{m}^{2}$ among Japanese women, twin pregnancy, diabetes mellitus/gestational diabetes mellitus, and connective tissue diseases such as rheumatoid arthritis, systemic lupus erythematosus, Sjogren's syndrome, antiphospholipid syndrome, and some thyroid diseases 
associated with autoantibody are risk factors for PE. ${ }^{24-26}$ In our study population, as many as $49 \%(44 / 89)$ of women were aged 35 years or more. In the 14 women who developed PE, $43 \%(6 / 14)$ were aged 40 years or more, $29 \%(4 / 14)$ were twin pregnancies, and all of the remaining 6 women with singleton pregnancies and aged $<40$ years had risk factors for PE including systemic lupus erythematosus in two women, advanced maternal age ( $\geq 35$ years) in two women, Sjogren's syndrome in one woman and diabetes mellitus in one woman. Thus, since our study participants were prone to PE, larger controlled studies in general pregnant women are required to determine the precise features of screening characteristics of NCR for prediction of PE.

\section{CONCLUSIONS}

Detailed investigations of changes in urinary NCR and PCR in normal and PE pregnancies revealed that urinary NCR and PCR increased gradually with advancing gestation in PE pregnancies, while NCR did not show significant changes despite the gradual increases in PCR in normotensive pregnancy. These observations suggested that urinary NCR may be a more efficient means of detecting women at higher risk of developing PE compared with urinary PCR.

Contributors TZ and IF contributed to the study design, sample collection, determination of urine variables and drafting of the manuscript. RA, KK, KC TU, SI, TY and MM were responsible for obtaining informed consent from participants, sample collection and discussion on the study design. HM contributed to the study design, drafting of the manuscript and supervision of this study.

Funding This study was supported by a Grant-in Aid for Scientific Research from the Ministry of Education, Science, Sports and Culture of Japan (number 25462546).

\section{Competing interests None declared.}

Patient consent Obtained.

Ethics approval Institutional Review Board of Hokkaido University Hospital (013-3999, April 30, 2014).

Provenance and peer review Not commissioned; externally peer reviewed.

Data sharing statement No additional data are available.

Open Access This is an Open Access article distributed in accordance with the Creative Commons Attribution Non Commercial (CC BY-NC 4.0) license, which permits others to distribute, remix, adapt, build upon this work noncommercially, and license their derivative works on different terms, provided the original work is properly cited and the use is non-commercial. See: http:// creativecommons.org/licenses/by-nc/4.0/

\section{REFERENCES}

1. Ruotsalainen V, Ljungberg $P$, Wartiovaara J, et al. Nephrin is specifically located at the slit diaphragm of glomerular podocytes. Proc Natl Acad Sci USA 1999:96:7962-7.

2. Mundel $P$, Shankland SJ. Podocyte biology and response to injury J Am Soc Nephrol 2002;13:3005-15.
3. Tryggvason K, Jaakko Patrakka J, Wartiovaara J. Hereditary proteinuria syndromes and mechanisms of proteinuria. $N$ Engl J Med 2006;354:1387-401.

4. Brinkkoetter PT, Ising C, Benzing T. The role of the podocyte in albumin filtration. Nat Rev Nephrol 2013;9:328-36.

5. Kelder TP, Penning ME, Un HW, et al. Quantitative polymerase chain reaction-based analysis of podocyturia is a feasible diagnostic tool in preeclampsia. Hypertension 2012;60:1538-44.

6. Kandasamy Y, Smith R, Lumbers ER, et al. Nephrin-a biomarker of early glomerular injury. Biomark Res 2014;2:21.

7. Garovic VD, Wagner SJ, Turner ST, et al. Urinary podocyte excretion as a marker for preeclampsia. Am J Obstet Gynecol 2007;196:320.e1-7.

8. Konieczny A, Ryba M, Wartacz J, et al. Podocytes in urine, a nove biomarker of preeclampsia? Adv Clin Exp Med 2013;22:145-9.

9. Craici IM, Wagner SJ, Bailey KR, et al. Podocyturia predates proteinuria and clinical features of preeclampsia: Iongitudinal prospective study. Hypertension 2013;61:1289-96.

10. Garovic VD, Wagner SJ, Petrovic LM, et al. Glomerular expression of nephrin and synaptopodin, but not podocin, is decreased in kidney sections from women with preeclampsia. Nephrol Dial Transplant 2007;22:1136-43.

11. Zhao S, Gu X, Groome LJ, et al. Decreased nephrin and GLEPP-1, but increased VEGF, Flt-1, and nitrotyrosine, expressions in kidney tissue sections from women with preeclampsia. Reprod Sci 2009;16:970-9.

12. Wang $\mathrm{Y}$, Zhao S, Loyd $\mathrm{S}$, et al. Increased urinary excretion of nephrin, podocalyxin, and $\beta$ ig-h3 in women with preeclampsia. Am J Physiol Renal Physiol 2012;302:F1084-9.

13. Yang GY, Lee KA, Park MH, et al. Urinary nephrin: a new predictive marker for pregnancies with preeclampsia and small-for-gestational age infants. Obstet Gynecol Sci 2013;56:22-8.

14. Son GH, Kwon JY, Lee S, et al. Comparison of serum and urinary nephrin levels between normal pregnancies and severe preeclampsia. Eur J Obstet Gynecol Reprod Biol 2013;166:139-44.

15. Jim B, Mehta S, Qipo A, et al. A comparison of podocyturia, albuminuria and nephrinuria in predicting the development of preeclampsia: a prospective study. PLOS ONE 2014;9:e101445.

16. Smith NA, Lyons JG, McElrath TF. Protein:creatinine ratio in uncomplicated twin pregnancy. Am J Obstet Gynecol 2010;203:381. e1-4.

17. Côté AM, Brown MA, Lam E, et al. Diagnostic accuracy of urinary spot protein:creatinine ratio for proteinuria in hypertensive pregnant women: systematic review. BMJ 2008;336:1003-6.

18. Brown MA, Lindheimer MD, de Swiet M, et al. The classification and diagnosis of the hypertensive disorders of pregnancy: statement from the International Society for the Study of Hypertension in Pregnancy (ISSHP). Hypertens Pregnancy 2001;20:IX-XIV.

19. NICE Clinical Guideline 107. Hypertension in Pregnancy; The Management of Hypertensive Disorders During Pregnancy. Issued 2010, last modified: January 2011. https://www.nice.org.uk/ guidance/cg107/resources/guidance-hypertension-in-pregnancy-pdf (accessed 26 Sep 2015).

20. American College of Obstetricians and Gynecologists; Task Force on Hypertension in Pregnancy. Hypertension in pregnancy. Report of the American College of Obstetricians and Gynecologists' Task Force on Hypertension in Pregnancy. Obstet Gynecol 2013;122:1122-31.

21. Magee LA, Pels A, Helewa M, et al, SOGC Hypertension Guideline Committee. Diagnosis, evaluation, and management of the hypertensive disorders of pregnancy: executive summary. $J$ Obstet Gynaecol Can 2014;36:575-6.

22. Morikawa M, Yamada T, Yamada T, et al. Pregnancy outcome of women who developed proteinuria in the absence of hypertension after mid-gestation. J Perinat Med 2008;36:419-24.

23. Akaishi R, Yamada T, Morikawa M, et al. Clinical features of isolated gestational proteinuria progressing to pre-eclampsia: retrospective observational study. BMJ Open 2014;4:e004870.

24. Morikawa M, Yamada T, Yamada T, et al. Effect of nulliparity, maternal age, and pre-pregnancy body mass index on the development of gestational hypertension and preeclampsia Hypertensin Res Pregnancy 2013;1:75-80.

25. Krotz S, Fajardo J, Ghandi S, et al. Hypertensive disease in twin pregnancies: a review. Twin Res 2002;5:8-14.

26. Beneventi F, Locatelli E, Caporali R, et al. Connective tissue diseases and autoimmune thyroid disorders in the first trimester of pregnancy. J Reprod Immunol 2016;114:32-7. 